\title{
Interleukin-1 Injected into Mammalian Brain Stimulates Astrogliosis and Neovascularization
}

\author{
Dana Giulian, Janet Woodward, Douglas G. Young, Joseph F. Krebs, and Lawrence B. Lachman' \\ Department of Neurology and Program of Neuroscience, Baylor College of Medicine, and 'Department of Cell Biology, \\ The University of Texas, M. D. Anderson Hospital and Tumor Institute, Houston, Texas 77030
}

\begin{abstract}
Interleukin-1 (IL-1), a protein produced by mononuclear phagocytes, helps to initiate the inflammatory response through its action upon a diverse population of cells. Recently this immunomodulator has been detected at sites of traumatized brain. As reported here, recombinant forms of IL-1 injected into the cerebral cortex of adult rats elicit not only astrogliosis but also new blood vessel growth. These responses are typical of brain injury and suggest that IL-1secreting inflammatory cells may mediate wound healing in the CNS.
\end{abstract}

Injury to the CNS of man often leads to irreversible structural changes and permanent loss of function. The cellular events at wound sites in the brain include the rapid appearance of inflammatory cells (Rio-Hortega, 1932; Ling, 1981; Giulian, 1987) and the subsequent growth of astroglia (Latov et al., 1979; Bignami and Dahl, 1976). The resulting dense collection of astroglial processes may prevent recovery of function by inhibiting the regeneration of neurons (Aguayo et al., 1981; Parés and Levine, 1982; Reier et al., 1983) and by retarding new myelin membrane formation (Blakemore and Crang, 1986). The mechanisms that control astrogliosis after brain injury are unknown.

Interleukin-1 (IL-1) is a pluripotent immunomodulator released by mononuclear phagocytes (Dinarello, 1984). It is believed that IL-1 acts as a growth factor to stimulate the prolifcration of lymphocytes (Dinarello, 1984) and fibroblasts at sites of inflammation (Leibovich and Ross, 1976; Postlewaite et al., 1984). Recent work has shown that stab wounds within the C.NS also contain high concentrations of IL-1 (Giulian and Lachman, 1985). We report here that recombinant IL-1, when infused into mammalian brain, will elicit astrogliosis and new blood vessel growth at the site of injection. Our observations suggest that secretion products from the immune system help to regulate wound healing in damaged brain.

\section{Materials and Methods}

Injection of immunomodulators into brain. Adult female rats (250-300 gm; Holtzman, Madison, WI) received $2 \mu$ intracerebral injections containing either 2 units of recombinant human IL- $1 \beta$ (rh-IL-1 $\beta$ ), 5 units of recombinant murine IL-1 (rm-IL-1), 10 units of recombinant human interleukin-2 (rh-IL-2), or 100 units of recombinant murine gamma interferon $(\mathrm{rm}-\mathrm{IF}-\gamma)$. We obtained $\mathrm{rm}-\mathrm{IL}-1$ as a gift from Dr. Peter

\footnotetext{
Received July 16, 1987; revised Nov. 5, 1987; accepted Nov. 27, 1987.

This work was supported by Grants NS23113 from NINCDS, EY04915 from NEI, a Teacher Investigator Award from NINCDS, and funds from the March of Dimes.

Correspondence should be addressed to D. Giulian, Department of Neurology, Baylor College of Medicine, One Baylor Plaza, Houston, $1 \times 77030$.
}

Copyright (C) 1988 Society for Neuroscience $0270-6474 / 88 / 072485-06 \$ 02.00 / 0$
LoMedico, Hoffman-LaRoche; rh-IL- $1 \beta$ was purchased from Cistron, $\mathrm{rm}-\mathrm{IF}-\gamma$ purchased from Genentech, and rh-IL-2 purchased from Cetus. All factors showed less than $0.05 \mathrm{ng} / \mathrm{ml}$ of endotoxin, as detected by the Limulus amoebocyte lysate assay (Associates of Cape Cod). Control injections of $2 \mu \mathrm{l}$ containing only the vehicle, PBS (pH 7.4), $100 \mathrm{ng}$ cytochrome C in PBS, or $100 \mathrm{ng}$ human serum albumin in PBS were placed at an identical position in the contralateral hemisphere.

Rats were anesthetized with $0.8-1.2 \mathrm{ml} / \mathrm{kg}$ of a cocktail containing $8.6 \mathrm{mg} / \mathrm{ml}$ xylazine (Miles Laboratories, Shawnee, KS), $1.4 \mathrm{mg} / \mathrm{ml}$ acepromazine (Tech America Group, Shawnee, KS), and $42.9 \mathrm{mg} / \mathrm{ml} \mathrm{ke-}$ tamine $\mathrm{HCl}$ (Bristol-Myers, Syracuse, NY). Samples were injected intracerebrally through a burr hole in the skull using a 5 microliter syringe (Hamilton, Reno, NE) mounted on a stereotaxic device (David Kopf Instruments, Tujunga, CA). Injections were placed $4.0 \mathrm{~mm}$ caudal to bregma, $2.0 \mathrm{~mm}$ lateral from the midline suture, and at a depth of 1.2 $\mathrm{mm}$ from the surface of the brain (Fig. 1). The rate of injection was 1 $\mu \mathrm{l} / \mathrm{min}$, and at completion of the injection $2 \mathrm{~min}$ were allowed before removing the syringe needle from the brain. All solutions contained a suspension of $5 \mu \mathrm{m}$ polystyrene microspheres $(0.25 \% \mathrm{vol} / \mathrm{vol})$ (Microspheres 15714, Polysciences, Warrington, PA) that was used to locate the site of injection.

Histology. The extent of astrogliosis was quantitated by scoring the number of nuclei for astroglia containing glial fibrillary acidic protein (GFAP) at the sites of injection. Five days after injection, animals were anesthetized and perfused with $50-75 \mathrm{ml}$ of heparin-PBS solution $(500$ USP U/liter; Elkins-Sinn, Cherry Hill, NJ), followed by $40-50 \mathrm{ml}$ of $3 \%$ formaldehyde in PBS (EM Science, Cherry Hill, NJ). The tissue was washed 3 times in PBS and repeatedly rinsed with a final solution of PBS containing $20 \%$ sucrose and $10 \%$ glycerol. The tissue was trimmed, frozen in O.C.T. compound (Tissue-Tek, Naperville, IL), and sectioned serially in the coronal plane ( $20 \mu \mathrm{m}$ thickness) using a freezing microtome (Minotome, Needham Heights, MA) at $-20^{\circ} \mathrm{C}$. The tissue sections were mounted onto agar-coated slides, treated with $0.1 \%$ Triton X-100 for $30 \mathrm{~min}$ at $37^{\circ} \mathrm{C}$, and washed with PBS. Tissue sections were incubated with $5 \%$ normal goat serum for $30 \mathrm{~min}$ at $37^{\circ} \mathrm{C}$, followed by washing with PBS. The primary antibody, rabbit immunoglobulins to bovine GFAP (Dako, Santa Barbara, CA), was diluted 1:100 in PBS containing $0.1 \%$ Triton $\mathrm{X}-100$ and applied to the slides for $2 \mathrm{hr}$ at $37^{\circ} \mathrm{C}$. After rinsing in PBS, biotinylated anti-rabbit $\mathrm{IgG}(10 \mathrm{mg} / \mathrm{ml}$; Vector Lab, Burlingame, CA) was applied for $30 \mathrm{~min}$ at $37^{\circ} \mathrm{C}$, followed by a $30 \mathrm{~min}$ incubation with HRP complex (Vectastain ABC Kit; Vector Laboratories, Burlingame, CA). The slides were incubated in $1 \mathrm{mg} / \mathrm{ml}$ diaminobenzidine tetrahydrochloride (Sigma) diluted $1: 1$ with $3 \%$ hydrogen peroxide in Tris- $\mathrm{HCl}(\mathrm{pH} \mathrm{8.2)}$. After $10 \mathrm{~min}$, the reaction was stopped with water. Peroxidase-stained sections were counterstained with hematoxylin to identify nuclei. The GFAP $(+)$ astroglia were also identified by indirect immunofluorescence using rhodamine-labeled goat anti-rabbit IgG (Bignami and Dahl, 1976; Giulian et al., 1986a) on sections prepared as described above. All tissue sections that contained an injection site were identified by the presence of polystyrene microspheres vicwcd by dark-field microscopy.

Peroxidase-stained GFAP $(+)$ astroglia found at control and experimental injection sites were examined by a light microscope with a drawing tube attachment $(250 \times)$. Ten to twelve tissue sections, all containing polystyrene microspheres, were used from each animal. The position of the needle tract, the location of the polystyrene microspheres, and the position of nuclei for GFAP( + ) astroglia were traced onto paper. The drawings of these tissue sections, extending from the most rostral 
Figure 1. Diagrams to illustrate the site and depth of intracerebral injection. $A$, Two microliter injections were placed $4.0 \mathrm{~mm}$ caudal to bregma, $2.0 \mathrm{~mm}$ lateral from the midline, at a depth of 1.2 $\mathrm{mm}$. Serial sections $20 \mu \mathrm{m}$ in thickness were taken throughout the injection site and stained for GFAP. Enlarged insert shows that GFAP $(+)$ cell numbers were determined from $300 \mu \mathrm{m}$ distance from the center of the injection site at increasing depths from the brain surface. Center of the injection site was located by coinjected polystyrene microspheres.
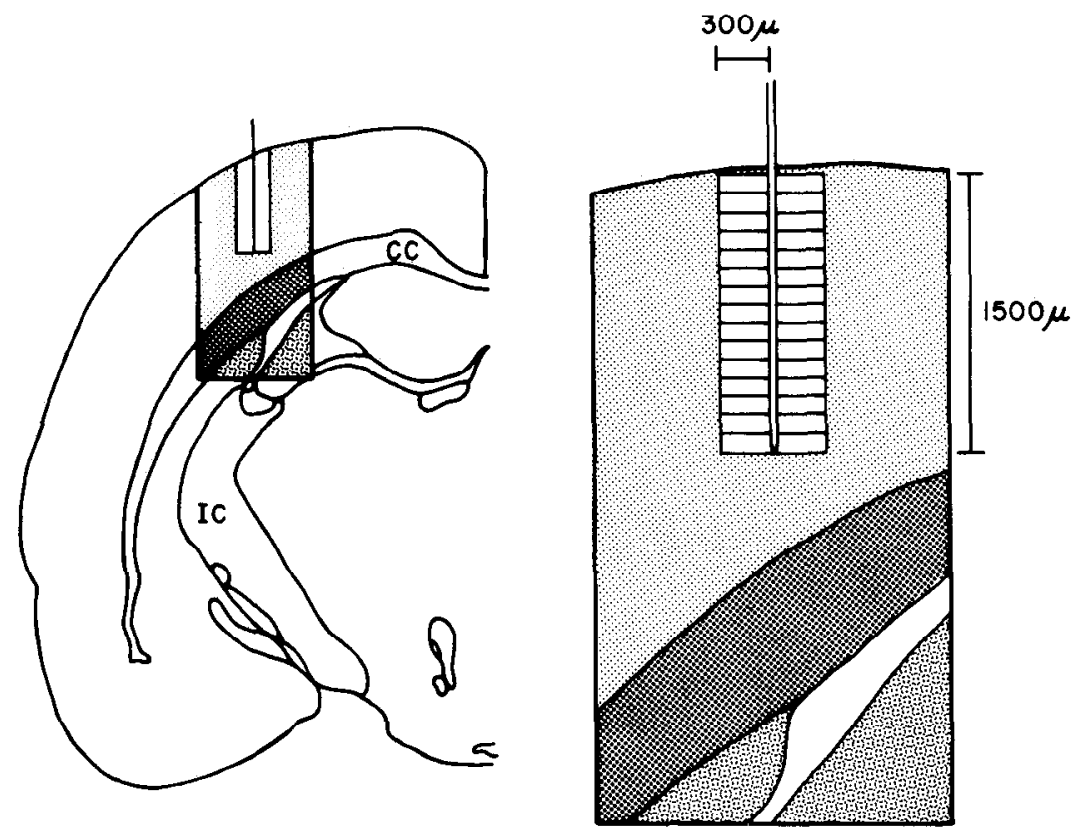

to the most caudal positions of the injection site, were overlayed onto a plastic sheet and the total number of astroglia determined for each animal. The number of cell nuclei from 3 or more animals for each experimental group was calculated and averaged, and scores were expressed as the mean number of nuclei $(100 \mu \mathrm{m})^{2}$ per tissue section.

We used the method of Gomori (1937) to stain reticulum along vessel walls. Indirect immunofluorescence techniques using anti-rabbit IgGL-rhodamine were used to identify laminin (rabbit antiserum 1:1250 from BRL, Gaithersburg, MD) and factor VIII (rabbit antiserum 1:4, from Ortho Diagnostics, Raritan, NJ).

Determination of $I L-1$ levels in injured brain. In order to determine the physiologic levels of IL-1 in the cerebral cortex of injured adult rat, we inflicted single stab wounds to the depth of $1.2 \mathrm{~mm}$ from the surface of the brain using a flame-heated \#26 needle mounted in a stereotaxic device (Giulian, 1987). Cylindrical biopsies of cerebral cortex ( $2 \mathrm{~mm}$ diameter, $5.0 \pm 0.2 \mathrm{mg}$ wet weight) were recovered after injury and placed in $1.0 \mathrm{ml}$ of chemically defined medium (Giulian et al., 1986a) for $15 \mathrm{hr}$ at $37^{\circ} \mathrm{C}$. The amount of IL-1 secreted into the conditioned medium was estimated by measuring biologic activity using ${ }^{3} \mathrm{H}$-thymidine incorporation by the D10.G cell line (Lachman et al., 1985). Units of IL-1 were calculated from a dose-response curve based upon rh-IL- $1 \alpha$ from Genzme.

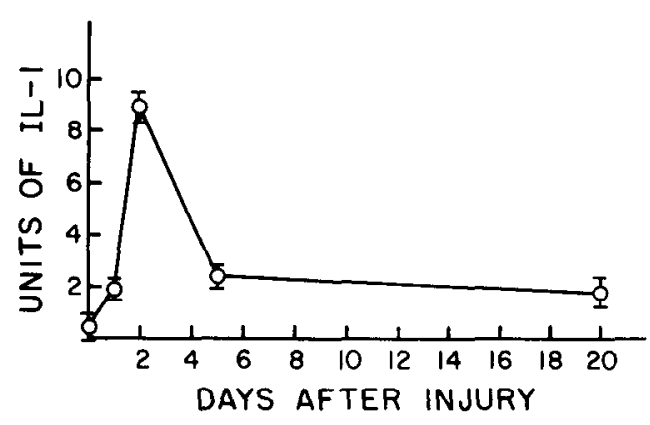

Figure 2. The appearance of IL-1 within the brain after penetrating injury. Stab wounds inflicted in the cerebral cortex of adult rats were biopsied at various times after injury and monitored for the secretion of IL-1. Normal brain released little biologic activity, as measured by the D.10.G cell line assay ( $<0.5$ units). In contrast, significant amounts of IL-1 were produced by tissue isolated $24 \mathrm{hr}$ after stab wounding. The peak of IL-1 production occurred at $2 \mathrm{~d}$, with elevations persisting for at least $20 \mathrm{~d}$. Data are units expressed as mean values $\pm \mathrm{SE}$. Each value was based on a minimum of 6 biopsies.

\section{Results}

Although IL-1 secretion in a normal adult brain biopsy is near the limits of detection, we observe nearly 2 units of secreted biologic activity within $1 \mathrm{~d}$ after a stab wound (Fig. 2). The peak of brain IL- 1 secretion ( $9.0 \pm 0.6$ units) occurred at $2 \mathrm{~d}$ postinjury, corresponding to that time when large numbers of mononuclear phagocytes appear at the site of damage (Giulian, 1987). Assuming that these observations reflected the physiologic concentrations of IL- 1 after penetrating injury to the brain, we tested the ability of 2-5 units of recombinant IL-1 to elicit astrogliosis in vivo. The location and depth of the injection into the cerebral cortex matched that of the stab wound.

Five days after injection, red cells and inflammatory cells could be identified within the needle tracts of all experimental or control injection sites. In all groups GF $\mathrm{P}(+)$ astroglia were found along the needle tracts, although striking increases in both cell number and intensity of GFAP staining were noted only in those sites injected with IL-1 (Figs. 3, $A, B$ ). The number of polystyrene microspheres injected into each animal was approximately the same in all groups, and there was no correlation

Table 1. Cylindrical biopsies of the injection sites were obtained from unfixed, heparin-PBS-perfused brains

\begin{tabular}{ll} 
Treatment $(n)$ & $\begin{array}{l}\text { Glutamine synthetase } \\
\text { activity } \\
(\mathrm{U} / \mathrm{mg})\end{array}$ \\
\hline rh-IL-1 $\beta(14)$ & $0.0868^{*} \pm 0.0100$ \\
rh-IL-2 (14) & $0.0609 \pm 0.0057$ \\
Cytochrome C (14) & $0.0608 \pm 0.0076$ \\
Control without injection (13) & $0.0503 \pm 0.0060$
\end{tabular}

Spccific enzymic activity of glutaminc synthetase (Rowe ct al., 1970) was measured in biopsies $5 \mathrm{~d}$ after injection, with activity expressed in units $(\mathrm{U}=\mu \mathrm{mol}$ of $\gamma$-glutamyl hydroxamic acid/min) per milligram protein \pm SEM. Factors injected include 2 units rh-IL- $1 \beta, 10$ units rh-IL-2, or $100 \mathrm{ng}$ cytochrome $C$. Only IL-1 stimulated a significant increase in enzymic activity when compared to controls. * Student's $t=3.13, d f=26, p<0.01, n$, Number of biopsies examined. 
A
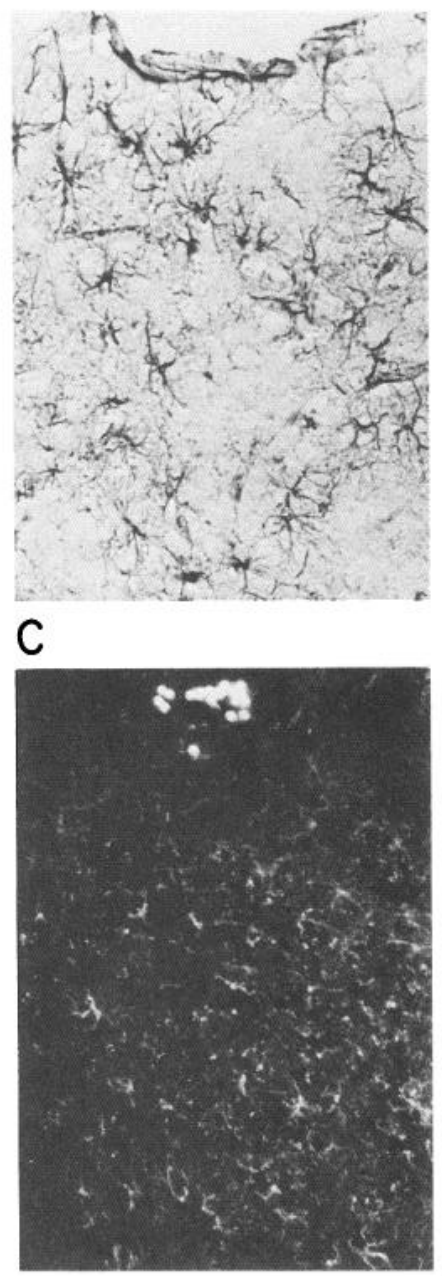

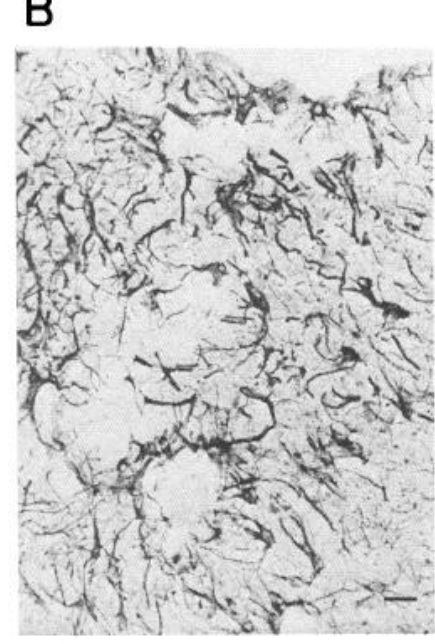

D

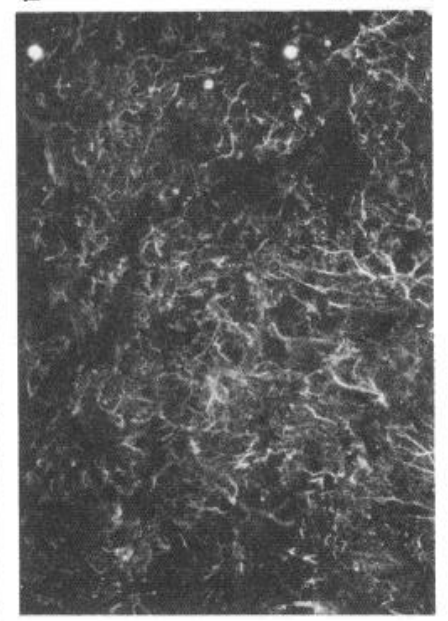

Figure 3. Photomicrographs of tissue sections stained for GFAP from brains injected 5 d earlier with PBS $(A, C)$ or 5 units of rm-IL-1 $(B, D)$. IL- 1 induced an increase in GFAP $(+)$ astroglia and hypertrophy of GFAP(+) astroglial processes. Astroglia were visualized by immunoperoxidase labeling of antibody to GFAP (upper panels) or by immunofluorescence with rhodamine-labeled antibody to GFAP (lower panels). The site of injection was located by the presence of polystyrene microspheres (arrows in lower panels). Bar, $20 \mu \mathrm{m}$.

between the number of beads and numbers of astroglia found at the injection sites (Fig. 3, C, D).

Quantitation of astroglia showed that increased cell numbers typically extended about $300-400 \mu \mathrm{m}$ to either side of the center of the injection site (Fig. 4). For this reason, we determined the mean number of nuclei from $\operatorname{GFAP}(+)$ astroglia for a distance of $300 \mu \mathrm{m}$ on either side of the injection, to a depth of 1100 $\mu \mathrm{m}$ from the brain's surface. These cell counts were averaged for all animals of a group, with each factor injection site compared with the contralateral control injection site. For this study, we examined more than $30,000 \mathrm{GFAP}(+)$ astroglia found at 34 injection sites. As shown in Figure 5, rm-IL-1 and rh-IL- $1 \beta$ increased the number of $\operatorname{GFAP}(+)$ astroglia 3-fold above that found at control injection sites or above those animals receiving rh-IL- 2 or rm-IF- $\gamma$. It should be noted that this scoring method could not distinguish cell migration, cell proliferation, or accumulation of GFAP as possible mechanisms to account for the

Table 2. Blood vessels at sites of intracerebral injection

Total blood vessel area at injection site

Treatment $(n)$ $\left(\mu \mathrm{m}^{2}\right)$

Control injection (50)

rm-IL-1 (16)

rh-IL-2 (13)

rm-IF- $\gamma(21)$

Control without injection (21)

$20,100 \pm 1700$

$69,800^{*} \pm 9100$

$20,200 \pm 2600$

$28,700 \pm 2600$

$11,600 \pm 1000$

$\overline{\text { Area of reticulum-stained blood vessels found at the site of intracerebral injection. }}$ Five days after injection, brain sections, $20 \mu \mathrm{m}$ in thickness, were stained for reticulum and the total vessel area measured by a Zeiss Videoplan Analyzer. The region evaluated was determined by the position of polystyrene microspheres 300 $\mu \mathrm{m}$ to either side of the center of the injection, to a depth of $1100 \mu \mathrm{m}$ from the surface of the brain. Factors injected include $2 \mu$ l volumes containing 5 units of rm-IL-1, 10 units of rh-IL-2, or 20 units of rm-IF- $\gamma$. Control injections of $2 \mu \mathrm{l}$ contained $100 \mathrm{ng}$ equine cytochrome C in PBS. Data are expressed as mean areas in $\mu \mathrm{m}^{2} \pm \mathrm{SE}$. Only IL-1 stimulated a significant increase in the formation of blood vessels when compared to control injection.

* Student's $t=5.30, d f=64, p<0.001$. $n$, Number of sections scored.

increase in numbers of GFAP(+) astroglia. Other control injections, including PBS, PBS with human serum albumin, or PBS with cytochrome $\mathrm{C}$, did not increase astroglial numbers (Fig. 5).

In addition to the histological changes associated with astrogliosis, increased levels of glutamine synthetase, an astroglial enzyme (Norenberg, 1979; Hallermayer et al., 1981), are known to occur in traumatized mammalian brain (Politis and Miller, 1985). For this reason, we also examined glutamine synthetase levels at sites of IL- 1 injections. We found that rh-IL- $1 \beta$, but not rh-IL-2, stimulated significant increases in specific enzymic activity as compared to control injections of cytochrome C (Table 1). All injected sites showed greater enzymic activity than that found in normal uninjected tissue controls. The IL-1-induced increase in glutamine synthetase activity is similar to elevations found in crushed optic nerve of rat (Politis and Miller, 1985), and supports the idea that IL-1 has an astroglial-stimulating effect in vivo that mimics the naturally occurring astroglial response to brain injury. Although IL-1 stimulates the activity of glutamine synthetase, it does not alter levels of the oligodendroglial enżyme $2^{\prime}, 3^{\prime}$ cyclic nucleotide $3^{\prime}$ phosphohydrolase when tested in vitro and in vivo (data not shown). Further evidence of the specificity of the action of IL-1 comes from in vitro studies that demonstrated that IL-1 stimulates the growth of astroglia, but not of oligodendroglia (Giulian and Lachman, 1985; Giulian et al., 1986b).

We also found an increased number of astroglial processes abutting blood vessels at sites of IL-1 injection. Since neovascularization is a common finding at sites of brain injury (Yoshida et al., 1986), we monitored blood vessel formation near injection sites by staining for reticulum (Gomori, 1937), for laminin (Foidart et al., 1980), and for factor VIII (Hoyer et al., 1973). All 3 techniques showed increased vessel numbers, as well as increased vessel tortuosity at sites injected with IL-1 (Fig. 6). The reticulum stain demonstrated a 3-4-fold increase in total vessel area at IL-1 injection sites compared to control cytochrome C injections (Table 2). The increase in numbers and in tortuosity of blood vessels induced by IL-1 is similar to those changes associated with vessels found at sites of brain infarction (Yoshida et al., 1986). 

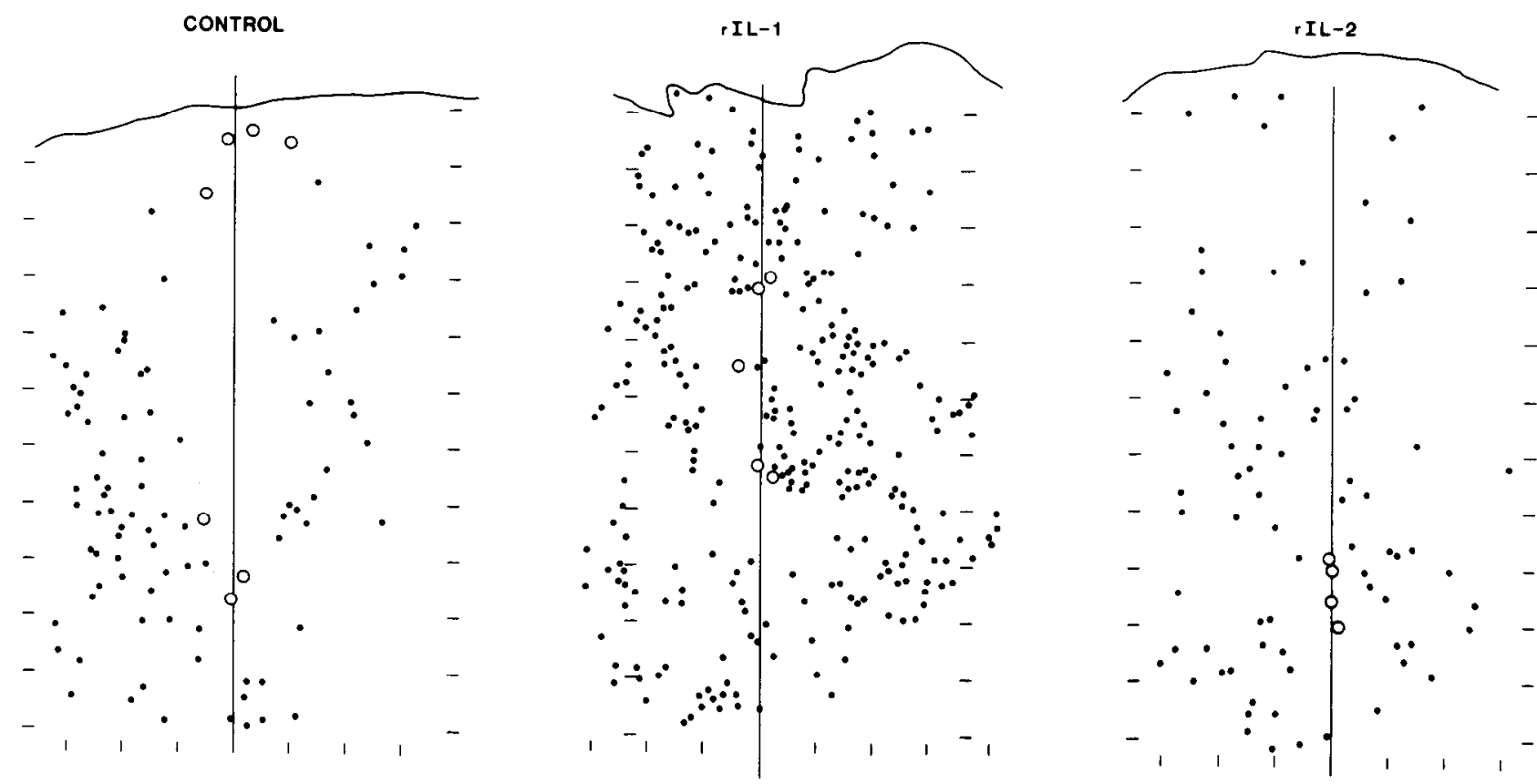

Figure 4. Camera lucida drawings of IL-1-induced astrogliosis. Astroglia found at injection sites for rm-IL-1, rh-IL-2, and PBS control injections were viewed at $250 \times$ following staining with GFAP. Open circles indicate $5 \mu \mathrm{m}$ polystryene microspheres that were used to determine the center of each injection. Closed circles indicate the location of nuclei of GFAP $(+)$ astroglia. Bars depict $100 \mu \mathrm{m}$ increments from the surface of brain in the vertical axis and from the center of injection site in the horizontal axis. These data, taken from a single tissue section, were averaged with $10-$ 12 additional sections from each animal to give a mean cell score, as shown in Figure 5.

Figure 5. The number of nuclei for $\mathrm{GFAP}(+)$ astroglia found at the injection sites for rm-IL-1 $(A)$, rh-IL-1 $\beta(B)$ rh-IL-2 $(C)$, and rm-IF- $\gamma(D)$ were expressed as the mean number of nuclei \pm SEM at given depths from the surface of the brain, as found in $100 \mu \mathrm{m}$ squares at a distance up to $300 \mu \mathrm{m}$ from the center of the injection sites in each 20 $\mu \mathrm{m}$-thick brain section examined. These mean values were obtained from 10 12 tissue sections cut in the coronal plane through the site of injection. Control injections in the contralateral hemisphere were scored in an identical fashion (open circles), and included PBS $(A, C), 100 \mathrm{ng}$ human serum albumin $(B)$, or $100 \mathrm{ng}$ equine cytochrome $\mathrm{C}(D)$. Data were also obtained from uninjected sites (open triangles, $A$ ). The injections were 5 units of rm-IL-1 $(n=$ $6), 2$ units of rh-IL- $1 \beta(n=4), 10$ units of rh-IL-2 $(n=4)$, or 100 units of rm$\operatorname{IF}-\gamma(n=3)$.

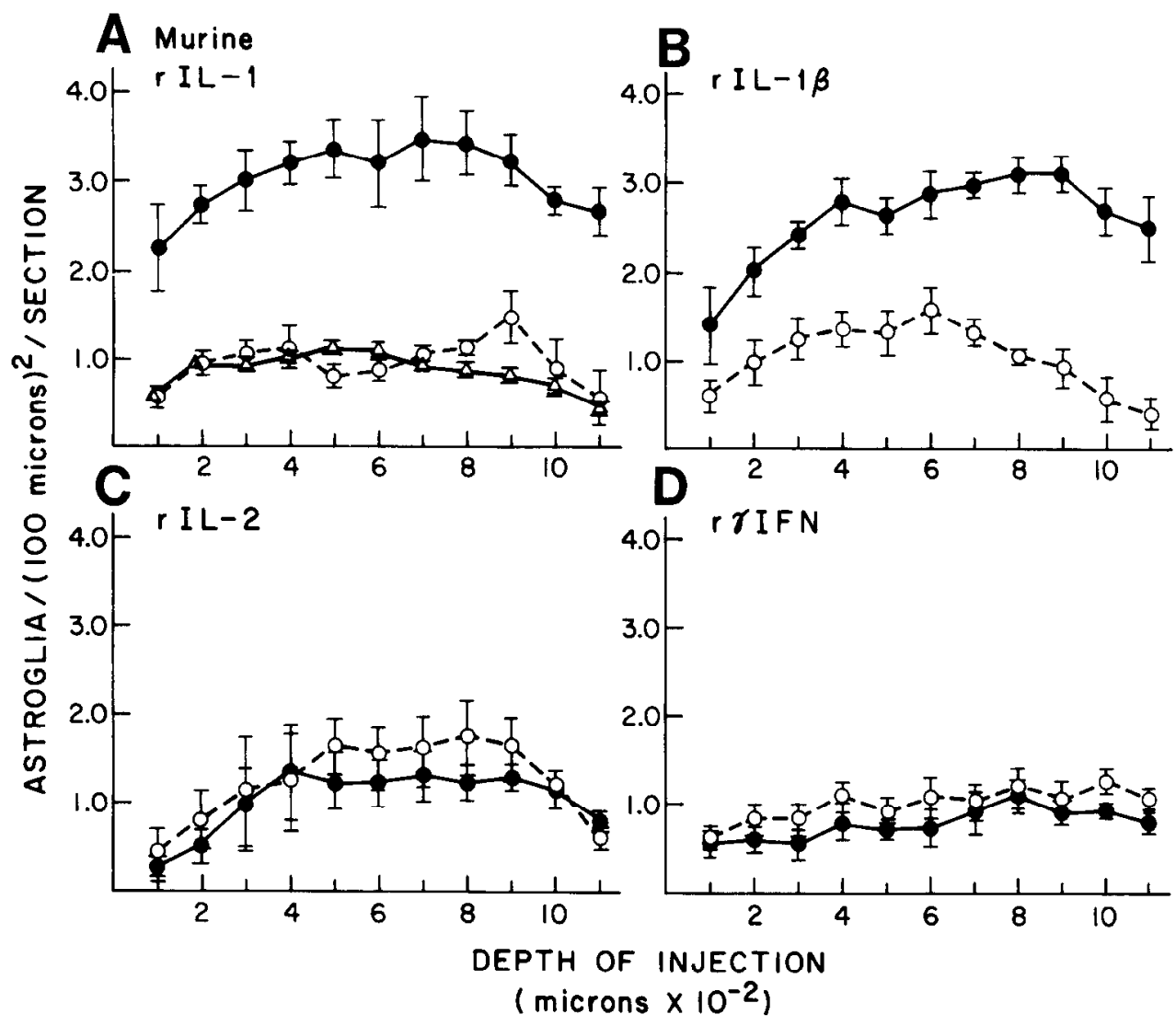



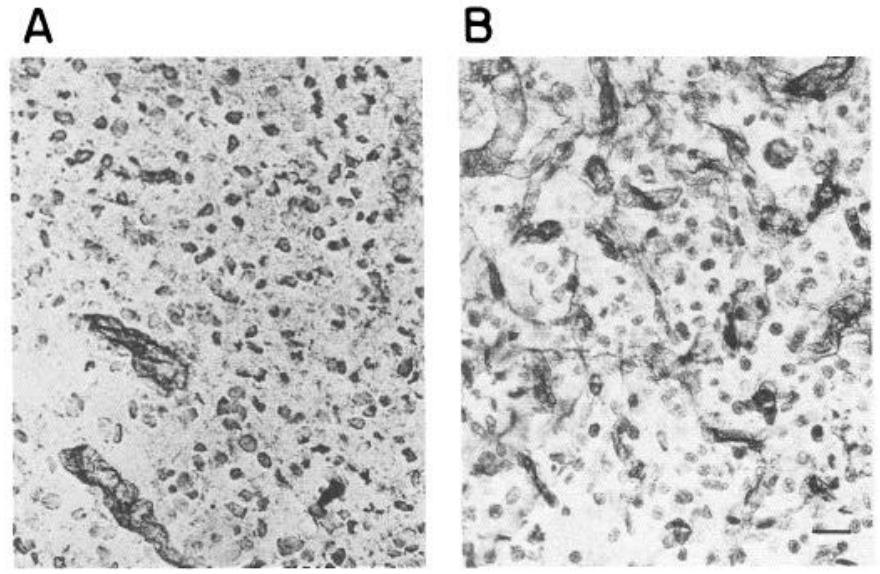

C
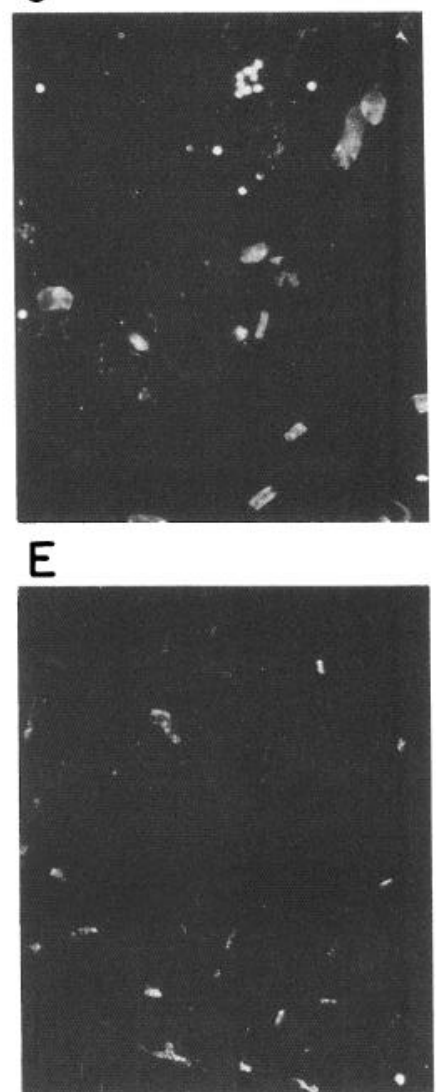

D

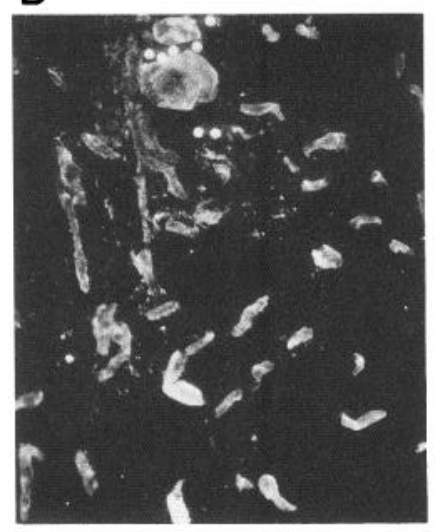

$\mathrm{F}$

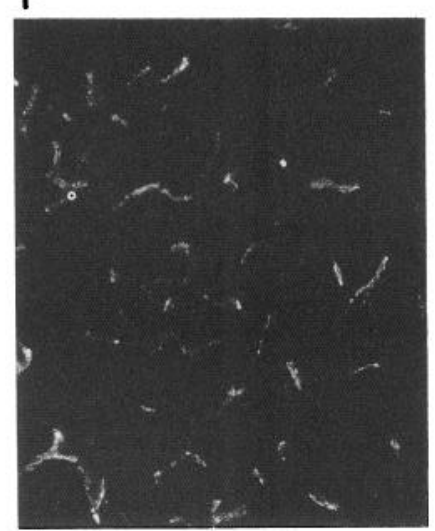

Figure 6. Photomicrographs showing blood vessels found after intracerebral injection of IL-1. The rh-IL-1 $\beta(B)$ injection showed an increase in the number of reticulum-stained vessels, as well as an increase in lumen size, when compared to PBS injection $(A)$. Laminin staining of capillaries near the sites of a control injection identified basement membrane of blood vessels $(C)$, while an increased number of laminin-stained capillaries were evident at the site of rh-IL-1 $\beta$ injection $(D)$. Staining for factor VIII demonstrated that rh-IL- $1 \beta$ induced an increase in capillary endothelium $(F)$, as compared to control injection sites $(E)$. Bar, $20 \mu \mathrm{m}$.

\section{Discussion}

The immunomodulator IL-1 has been shown to mediate inflammatory responses outside the CNS by stimulating lymphocyte proliferation and by promoting scar formation (Dinarello, 1984). Using both native and recombinant forms, our laboratory has shown that IL-1 is also a mitogen for astroglia in vitro (Giulian and Lachman, 1985; Giulian et al., 1986b). Because this growth factor is found in high concentrations at sites of penetrating brain injury (Giulian and Lachman, 1985), we have proposed that it may help to mediate astrogliosis growth in the CNS. To test this hypothesis, we infused recombinant forms of various immunomodulators into the cerebral cortex of rat and monitored astroglial responses at the site of injection. As reported here, only IL-1, and not IL- 2 or IF- $\gamma$, induced astrogliosis typical of brain injury. The in vivo action of physiologic concentrations of IL-1 upon the brain suggests that it does in fact mediate glial responses after brain injury. Second, our observations link secretion products of the immune system to tissue repair of the CNS.

What is the source of brain IL-1? Outside the CNS, mononuclear phagocytes are recognized as the most potent secretors of IL-1 (Dinarello, 1984). Study of different injury models suggests that the type of injury determines the type of inflammatory cell present. For example, penetrating wounds of the brain contain both macrophage and activated microglia (Rio-Hortega, 1932; Ling, 1981; Giulian, 1987), while axotomized cranial nerves contain only microglia (Kreutzberg and Barron, 1978). Both classes of brain mononuclear phagocyte, blood-borne macrophage and ameboid microglia, have been found to release IL-1 (Giulian and Baker, 1985, 1986; Giulian, 1987).

We also observed that IL-1, infused into the brain, stimulated blood vessel growth. Although there is no in vitro data to show IL-1 as an endothelial mitogen, IL-1 elicits angiogenesis in the cornea of rabbits (Prendergast et al., 1987). Futher work will be necessary to determine whether IL-1 acts directly upon brain capillaries as an angiogenic factor (Folkman and Klagsburn, 1987), or indirectly, perhaps by stimulating astroglia-endothelial cell interactions. Regardless of the cellular mechanisms, the net effect of intracerebral infusion of IL-1 is astrogliosis, with concomitant neovascularization.

Our data suggest a role for IL-1 as a regulator of cell growth and wound healing in the brain. We believe that inflammatory cells at the site of injury help to control astrogliosis and blood vessel growth in damaged CNS. Therapies to inhibit IL-1-secreting cells may therefore reduce the structural changes that occur after brain trauma.

\section{References}

Aguayo, A. J., S. David, and G. M. Bray (1981) Influences of the glial environment on the elongation of axons after injury: Transplantation studies in adult rodents. J. Exp. Biol. 95: 231-240.

Bignami, A., and D. Dahl (1976) The astroglial response to stabbing. Immunofluorescence studies with antibodies to astrocyte-specific protein (GFA) in mammalian and submammalian vertebrates. Neuropathol. Appl. Neurobiol. 2: 99-110.

Blakemore, W. F., and A. J. Crang (1986) The effect of injecting autologous Schwann cells into areas of demyelination in the cat spinal cord. Tenth International Congress of Neuropathology, Stockholm, A84.

Dinarello, C. A. (1984) Interleukin-1. Rev. Infect. Dis. 6: 51-95.

Foidart, J. M., E. W. Bere, M. Yaar, S. I. Rennard, M. Gullino, G. R. Martin, and S. I. Katz (1980) Distribution and immunoelectron microscopic localization of laminin, a noncollagenous basement membrane glycoprotein. Lab Invest. 42: 336-342.

Folkman, J., and M. Klagsburn (1987) Angiogenic factors. Science 235: 442-447.

Giulian, D. (1987) Ameboid microglia as effectors of inflammation in the central nervous system. J. Neurosci. Res. 18: 155-171.

Giulian, D., and T. J. Baker (1985) Peptides released by ameboid microglia regulate astroglial proliferation. J. Cell Biol. 101: 24112415 . 
Giulian, D., and T. J. Baker (1986) Characterization of ameboid microglia isolated from developing mammalian brain. J. Neurosci. 6 2163-2178.

Giulian, D., and L. B. Lachman (1985) Intcrlcukin-1 stimulation of astroglial proliferation after brain injury. Science 228: 497-499.

Giulian, D., R. Allen, T. J. Baker, and Y. J. Tomozawa (1986a) Brain peptides and glial growth. I. Glia-promoting factors as regulators of gliogenesis in the developing and injured central nervous system. Cell. Biol. 102: 803-811.

Giulian, D., T. J. Baker, L. N. Shin, and L. B. Lachman (1986b) Interleukin-1 of the central nervous system is produced by ameboid microglia. J. Exp. Med. 164: 594-604.

Gomori, A. (1937) Silver impregnation of reticulum in paraffin sections. Am. J. Pathol. 13: 993-1001.

Hallermayer, K., C. Harmening, and B. Hamprecht (1981) Cellular localization and regulation of glutamine synthetase in primary cultures of brain cells from newborn mice. J. Neurochem. 37: 43-52.

Hoyer, L. W., R. P. de los Santos, and J. R. Hoycr (1973) Antihemophilic factor antigen localization in endothelial cells by immunofluorescent microscopy. J. Clin. Inv. 52: 2737-2744.

Krelitzberg, G. W., and I. C. D. Barron (1978) 5'-Nucleotidase of microglial cells in the facial nucleus during axonal reaction. J. Neurocytol. 7: 601-610.

Lachman, L. B., L.-C. Shih, and D. C. Brown (1985) Interleukin-1 from human leukemic monocytes. Methods Enzymol. 116: 467-479.

Latov, N., G. Nilaver, E. A. Zimmerman, W. G. Johnson, A.-J. Silverman, R. Defendini, and L. Cote (1979) Fibrillary astrocytes proliferate in response to brain injury. Dev. Biol. 72: 381-384.

I eibovich, S. J., and R. Ross (1976) A macrophage-dependent factor that stimulates the proliferation of fibroblasts in vitro. Am. J. Pathol. 84: $501-514$.
Ling, E. A. (1981) The origin and nature of microglia. In Advances in Cell Neurobiology, vol. 2, S. Fedoroof and L. Hertz, eds., pp. 33-82, Academic, New York.

Norcnberg, M. D. (1979) The distribution of glutamine synthetase in the rat central nervous system. J. Histochem. Cytochem. 27: 756762.

Paré, M., and R. L. Levine (1982) Long-term degeneration renders central tracts refractory to penetration by regenerating optic fibers. Brain Res. 243: 360-362.

Politis, M. J., and J. E. Miller (1985) Post-traumatic alterations in glutamine synthetase activity in peripheral and central nerves. Brain Res. 359: 183-186.

Postlewaite, A. E., L. B. Lachman, and A. H. Kang (1984) Induction of fibroblast proliferation by interleukin-1 derived from human monocytic leukemia cells. Arthritis Rheum. 27: 995-1001.

Prendergast, R. A., G. A. Lutty, and C. A. Dinarello (1987) Interleukin-1 induces corneal vascularization. Inv. Ophthalmol. (Suppl.) 28: A100.

Reier, P. J., L. Stensaas, and L. Guth (1983) The astrocytic scar as an impediment to regeneration in the CNS. In Fundamentals of Spinal Cord Reconstruction, D. D. Kao, L. Stensaas, and L. Guth, eds., p. 163, Raven, New York.

Rio-Hortega, P. (1932) Microglia. In Cytology and Cellular Pathology of the Nervous System, vol. 2, W. Penfield, ed., pp. 481-584, Paul B. Hoeber, New York

Rowe, W., R. Ronzio, V. Wellner, and A. Meister (1970) Glutamine synthetase (sheep brain). Methods Enzymol. 17A: 900-910.

Yoshida, Y., F. Ikata, and M. Yamada (1986) Proliferation of reactive microvessels in experimental infarction: Chronological and threedimensional observation. 10th International Congress of Neuropathology, Stockholm, A416. 